\title{
Breaking Open the Closed Nature of Japanese Forestry
}

\author{
Katsushi Mizuno ${ }^{1}$, Go Igusa ${ }^{2}$, Eiji Takeda ${ }^{3}$, Takumu Doi ${ }^{4}$, Jun Omata ${ }^{5}$ \\ ${ }^{1}$ School of Commerce, Meiji University, Tokyo, Japan \\ ${ }^{2}$ School of Economics, Matsuyama University, Ehime, Japan \\ ${ }^{3}$ Commercial Course, Matsuyama Junior college, Ehime, Japan \\ ${ }^{4}$ The Organization for the Strategic Coordination of Research and Intellectual Properties at Meiji University, Tokyo, \\ Japan \\ ${ }^{5}$ Graduate School of Political Science and Economics, Meiji University, Tokyo, Japan \\ Correspondence: Go Igusa, School of Economics, Matsuyama University, Bunkyocho 4-2, Matsuyama, Ehime, Japan.
}

Received: January 18, 2017

doi:10.11114/ijsss.v5i3.2240

\author{
Accepted: February 17, $2017 \quad$ Available online: February 22, 2017 \\ URL: https://doi.org/10.11114/ijsss.v5i3.2240
}

\begin{abstract}
We have applied the system-wide approach, a theory developed by the economist $\mathrm{H}$. Theil, to input-output analysis to demonstrate the closed nature of forestry in Japan. We have also advocated the necessity of opening up the forestry industry in order to optimize production (minimize costs). Specifically, with the methodology employed here, we calculated input coefficients for Japanese forestry using input-output tables. We compared actual input coefficients with the input coefficients calculated to achieve optimal production. The results revealed that intermediate product transactions among forestry industry members were about $12 \%$ above the amount required for forestry to achieve optimal production, while intermediate product transactions with other industries were about $11 \%$ too low. This means that forest-related commissioned projects are carried out primarily by forestry players, so work is not being allocated to other industries. The results lead us to the conclusion that forestry in Japan is closed and that commissioned projects should be allocated to other sectors. We show compelling examples from prior research on opening up forestry to the construction industry and nonprofit organizations. Opening forestry projects to other sectors will improve forestry technologies in those sectors and lead to technological innovation in Japanese forestry.
\end{abstract}

Keywords: system-wide approach, input-output analysis, the closed nature of forestry in Japan, input coefficients, opening forestry projects to other sectors

\section{Objectives and Prior Research}

\subsection{Objectives}

Japan's forestry industry has long been viewed as closed. Reasons include the prevalence of specialized practices and circumstances that make it difficult for other industries to enter the market. However, this makes Japanese forestry economically inefficient.

The objective of this paper is to use input-output analysis to demonstrate the closed nature of Japanese forestry and present proposals for opening it. The reason for employing input-output analysis is that it allows us to look into the state of business between forestry and other industries, as well as ways to boost business with other industries in order to optimize forestry production. We will employ the economic theory called the system-wide approach, developed by $\mathrm{H}$. Theil, adapting it to input-output analysis. We derive input coefficients that elicit optimal production and compare them with actual input coefficients. In doing so, we show that forestry approaches optimal production when it deals more actively in intermediate products with other industries. Simply put, we recommend that the industry's closed structure be opened. Specifically, we propose breaking down the insularity of Japanese forestry by opening it up to the construction industry or to such sectors as nonprofit organizations (NPOs).

\subsection{Prior Research}

We use the system-wide approach of Theil (1980b) as our theoretical basis. Theil demonstrates the feasibility of applying input-output analysis and presents the formulas to be used. However, Theil stopped short of the comparative analysis of input coefficients developed in this paper. This is the first Japanese study showing the practical application 
of input-output analysis using a system-wide approach.

Yamamoto (2007) uses input-output analysis to research forestry in Japan by comparing it with forestry in Austria. He examines the connection between the intermediate forestry products market and domestic final demand from the viewpoint of ripple effects. However, he does not opine on how to end forestry's insularity, nor does he discuss which input coefficients would achieve optimal production - things that this paper does. His is a single-point-in-time analysis as of 2000, unlike this paper, which conducts a time-series analysis from the mid-1990s through 2011.

Other prior research takes the stance that entities implementing forest management should be expanded beyond the forestry industry. Okumura and Katsura (2006) and Yamamoto (2003) advocated the desirability of expanding forest management to forest volunteers. They analyzed the significance and status of forest volunteers in Japan and also surveyed forest owners on the receiving end, finding the top response to be "(the involvement of forest volunteers) promises to increase productivity." Yoneda (2012) advocated expansion to the construction sector. She surveyed the construction industry to explore the possibility of its participation in forestry. However, none of these studies went beyond identifying the intentions of the potential participants and the barriers they might face, and they did not demonstrate any interindustry metrics that would be appropriate from the viewpoint of economic theory.

Our intent here is to use these studies as a base to advance the research and address topics that they did not, with the objective being to break down the insularity of Japanese forestry.

\section{Building and Estimating the Input-Output Model}

\subsection{Using Input-output Tables to Understand the Situation}

Next, to analyze forestry using input-output tables, we adopted the analytical methodology of classifying the normal input-output tables into two categories: "forestry" and "total of other sectors" (Table 1). Horizontally, we show forestry, the total for other sectors, final demand, and the domestic production. Vertically, we show forestry, the total for other sectors, capital stock (K), labor (L), and. the domestic production.

Table 1. 2 x 2 input-output table

\begin{tabular}{ccccc}
\hline & Forestry & Total other & Final demand & $\begin{array}{c}\text { Domestic production } \\
\text { (gross outputs) }\end{array}$ \\
\hline Forestry & $\mathrm{q}_{11}$ & $\mathrm{q}_{12}$ & $\mathrm{q}_{1}, 0$ & $\mathrm{z}_{1}$ \\
Total other & $\mathrm{q}_{21}$ & $\mathrm{q}_{22}$ & $\mathrm{q}_{2}$ \\
$\mathrm{~K}$ & $\mathrm{~K}_{1}$ & $\mathrm{~K}_{2}$ & \\
$\mathrm{~L}$ & $\mathrm{~L}_{1}$ & $\mathrm{~L}_{2}$ & \\
$\begin{array}{c}\text { Domestic production } \\
\text { (gross outputs) }\end{array}$ & $\mathrm{C}_{1}$ in nominal terms & $\mathrm{C}_{2}$ in nominal terms & & \\
\hline
\end{tabular}

We represent intermediate input quantities as $\mathrm{q}_{11}, \mathrm{q}_{12}, \mathrm{q}_{21}, \mathrm{q}_{22}$; final demand as $\mathrm{q}_{1},{ }_{0}, \mathrm{q}_{2},{ }_{0}$; horizontal total the domestic production as $\mathrm{z}_{1}, \mathrm{z}_{2}$; capital stock as $\mathrm{K}_{1}, \mathrm{~K}_{2}$; and labor as $\mathrm{L}_{1}, \mathrm{~L}_{2}$. The quantities shown are actual values for the base year 2005. Note that the domestic production figures at the very bottom of the columns on the horizontal axis are the costs of forestry and all other sectors. These costs are shown as nominal values $\mathrm{C}_{1}$ and $\mathrm{C}_{2}$.

Using this structure, we prepared input-output tables for the period 1995-2011 ${ }^{1}$ (Note 1).

\subsection{Demand Equations and Estimations Using Input-output Analysis}

Let's explain Theil's system-wide approach. The equation for the system-wide approach is given below. By minimizing cost, we can obtain the equation for input demand that describes the demand for each factor of production by production volume and the price of each factor.

$$
\begin{aligned}
& \mathrm{f} 1 \mathrm{dln} q_{1}=\theta_{1} \gamma \mathrm{dln} z+\pi_{11} \mathrm{dln} p_{1}+\pi_{12} \mathrm{dln} \mathrm{p}_{2} \\
& \mathrm{f} 2 \mathrm{dln} \mathrm{q}_{2}=\theta_{2} \gamma \mathrm{dln} \mathrm{l}+\pi_{21} \mathrm{dln} \mathrm{p}_{1}+\pi_{22} \mathrm{dln} \mathrm{p}_{2}
\end{aligned}
$$

Here, $f_{1}$ and $f_{2}$ denote the share of each production factor (the percentage of each production factor's cost to total costs), and $\theta_{1}$ and $\theta_{2}$ denote the share of each production factor (the percentage of production factor cost increases to total cost increases). $\mathrm{q}_{1}$ and $\mathrm{q}_{2}$ are production factor quantities, and $\mathrm{p}_{1}$ and $\mathrm{p}_{2}$ are production factor prices. $\gamma$ is the reciprocal of scale elasticity. $\pi_{11}, \pi_{12}, \pi_{21}$, and $\pi_{22}$ are substitute parameters (Slutsky coefficients). $\mathrm{z}$ indicates domestic production such that domestic production and production factor prices determine production factor quantities. What is unique here is that the variables are in the form of differentials. In is the natural logarithm such that, for example, dlnz gives the rate of increase or rate of growth of $\mathrm{z}$; other variables are also rates of growth or rates of price increases.

Theil (1980b) rewrote Equation (2), adapting it to input-output analysis:

$$
\begin{aligned}
& \mathrm{p}_{1} \mathrm{dq}_{1}=\left(\gamma \mathrm{p}_{1} \mathrm{q}_{1} / \mathrm{pz}\right) \mathrm{pdz}+\mathrm{C}\left(\pi_{11} \mathrm{dln} \mathrm{p}_{1}+\pi_{12} \mathrm{dln} \mathrm{p}_{2}\right) \\
& \mathrm{p}_{2} \mathrm{dq}_{2}=\left(\gamma \mathrm{p}_{2} \mathrm{q}_{2} / \mathrm{pz}\right) \mathrm{pdz}+\mathrm{C}\left(\pi_{21} \mathrm{dln}_{1}+\pi_{22} \mathrm{dln} \mathrm{p}_{2}\right)
\end{aligned}
$$


where $C$ is the total cost $\mathrm{p}_{1} \mathrm{q}_{1}+\mathrm{p}_{2} \mathrm{q}_{2}$.

At the same time, the following equation holds true for the row totals of the input-output table in Table 1:

$$
\begin{aligned}
& \mathrm{z}_{1}=\mathrm{q}_{11}+\mathrm{q}_{12}+\mathrm{q}_{1}, 0 \\
& \mathrm{z}_{2}=\mathrm{q}_{21}+\mathrm{q}_{22}+\mathrm{q}_{2}, 0
\end{aligned}
$$

Each variable corresponds to the variables in Table 1.

Next, we rephrase Equation (2) in accordance with the input-output table we prepared:

$$
\begin{aligned}
& \mathrm{p}_{1} \mathrm{dq}_{11}=\mathrm{a}_{11} \mathrm{~m}_{1} \mathrm{p}_{1} \mathrm{dz}_{1}+\mathrm{C}_{1} \pi_{11}^{1} \mathrm{dlnp}_{1}+\mathrm{C}_{1} \pi_{12}^{1} \mathrm{dlnp}_{2}+\mathrm{C}_{1} \pi^{1}{ }_{1 \mathrm{~K}} \mathrm{dlnp}_{\mathrm{K}}+\mathrm{C}_{1} \pi_{1 \mathrm{~L}}^{1} \mathrm{dlnp}_{\mathrm{L}} \\
& \mathrm{p}_{1} \mathrm{dq}_{12}=\mathrm{a}_{12} \mathrm{~m}_{2} \mathrm{p}_{2} \mathrm{dz}_{2}+\mathrm{C}_{2} \pi^{2}{ }_{11} \mathrm{dlnp}_{1}+\mathrm{C}_{2} \pi_{12}^{2} \mathrm{dln}_{2}+\mathrm{C}_{2} \pi^{2}{ }_{1 \mathrm{~K}} \mathrm{dlnp}_{\mathrm{K}}+\mathrm{C}_{2} \pi^{2}{ }_{1 \mathrm{~L}} \mathrm{dlnp}_{\mathrm{L}} \\
& \mathrm{p}_{2} \mathrm{dq}_{21}=\mathrm{a}_{21} \mathrm{~m}_{1} \mathrm{p}_{1} \mathrm{dz}_{1}+\mathrm{C}_{1} \pi_{21}^{1} \mathrm{dlnp}_{1}+\mathrm{C}_{1} \pi^{1}{ }_{22} \mathrm{dlnp}_{2}+\mathrm{C}_{1} \pi^{1}{ }_{2 \mathrm{~K}} \mathrm{dlnp}_{\mathrm{K}}+\mathrm{C}_{1} \pi_{2 \mathrm{~L}}^{1} \mathrm{dlnp}_{\mathrm{L}} \\
& \mathrm{p}_{2} \mathrm{dq}_{22}=\mathrm{a}_{22} \mathrm{~m}_{2} \mathrm{p}_{2} \mathrm{dz}_{2}+\mathrm{C}_{2} \pi_{21}^{2}{ }_{21} \mathrm{dlnp}_{1}+\mathrm{C}_{2} \pi_{22}^{2}{ }_{22} \mathrm{dln}_{2}+\mathrm{C}_{2} \pi^{2}{ }_{2 \mathrm{~K}} \mathrm{dln}_{\mathrm{K}}+\mathrm{C}_{2} \pi_{2 \mathrm{~L}}^{2} \mathrm{dlnp}_{\mathrm{L}}
\end{aligned}
$$

$\mathrm{p}_{\mathrm{K}}$ is the price of capital, and $\mathrm{p}_{\mathrm{L}}$ is the price of labor.

$$
\begin{aligned}
& \mathrm{m}_{1}=\gamma_{1} \mathrm{C}_{1} / \mathrm{p}_{1} \mathrm{z}_{1} \\
& \mathrm{~m}_{2}=\gamma_{2} \mathrm{C}_{2} / \mathrm{p}_{2} \mathrm{z}_{2}
\end{aligned}
$$

\begin{tabular}{|c|c|c|c|c|c|c|}
\hline & $\begin{array}{c}\text { Term } 1 \text { on the } \\
\text { right }\end{array}$ & $\begin{array}{c}\text { Term } 2 \text { on the } \\
\text { right }\end{array}$ & $\begin{array}{c}\text { Term } 3 \text { on the } \\
\text { right }\end{array}$ & $\begin{array}{c}\text { Term } 4 \text { on the } \\
\text { right }\end{array}$ & $\begin{array}{c}\text { Term } 5 \text { on the } \\
\text { right }\end{array}$ & $\begin{array}{l}\text { Coefficient of } \\
\text { determination }\end{array}$ \\
\hline Equation 1 & 0.0111 & -0.0783 & 0.0641 & 0.1707 & -0.2184 & 0.0969 \\
\hline Equation 2 & 0.0014 & 0.0000 & -0.0009 & 0.0001 & -0.0011 & 0.1676 \\
\hline Equation 3 & 0.1712 & 0.3568 & -0.4386 & -0.2271 & -0.1645 & 0.6218 \\
\hline Equation 4 & 0.6270 & -0.026 & 0.5252 & -0.0113 & 0.0532 & 0.8866 \\
\hline \multicolumn{7}{|c|}{ Table 3. the t-value } \\
\hline \multicolumn{2}{|c|}{$\begin{array}{l}\text { Term } 1 \text { on the } \\
\text { right }\end{array}$} & $\begin{array}{l}\text { Term } 2 \text { on the } \\
\text { right }\end{array}$ & $\begin{array}{c}\text { Term } 3 \text { on the } \\
\text { right }\end{array}$ & $\begin{array}{l}\text { Term } 4 \text { on the } \\
\text { right }\end{array}$ & $\begin{array}{c}\text { Term } 5 \text { on the } \\
\text { right }\end{array}$ & $\begin{array}{l}\text { Coefficient of } \\
\text { determination }\end{array}$ \\
\hline Equation 1 & 0.2006 & -0.4008 & 0.1045 & 0.8349 & -0.3128 & 0.2006 \\
\hline Equation 2 & 1.2269 & -0.0507 & -0.7859 & 0.3882 & -0.557 & 1.2269 \\
\hline Equation 3 & 3.9778 & 2.3618 & -0.925 & -1.437 & -0.3047 & 3.9778 \\
\hline Equation 4 & 4.7797 & -0.6259 & 3.8226 & -0.2533 & 0.2287 & 4.7797 \\
\hline
\end{tabular}

If imports are included in final demand, the row totals and column totals of the input-output table are equal, meaning that the nominal values are equal, so we have $C_{1}=p_{1} z_{1}$ and $C_{2}=p_{2} z_{2}$ with $m_{1}=\gamma_{1}$ and $m_{2}=\gamma_{2}$. In other words, $m_{1}$ and $m_{2}$ are the reciprocals of scale elasticity.

We computed these equations with the ordinary least squares method. The estimation period is 1995-2011. We imposed no constraints on parameter symmetry.

Table 2. Results of parameter estimation

The first term on the right is the parameter estimate for $\mathrm{a}_{11} \mathrm{~m}_{1}, \mathrm{a}_{12} \mathrm{~m}_{2,} \mathrm{a}_{21} \mathrm{~m}_{1,}$ and $\mathrm{a}_{22} \mathrm{~m}_{2}$. In addition, we show the value of the substitution parameter for the price term. With regard to the coefficient of determination, Equation (1) has a low value, but the others can be seen as having interpretability.

\section{Research on the Ideal Nature of Japanese forestry}

\subsection{Calculating Optimal Input Coefficients}

Let's solve for $\mathrm{m} 1$ and $\mathrm{m} 2$.

From Table 2, the following equations hold true:

$$
\begin{aligned}
& \mathrm{a}_{11} \mathrm{~m}_{1}=0.0111 \\
& \mathrm{a}_{12} \mathrm{~m}_{2}=0.0014 \\
& \mathrm{a}_{21} \mathrm{~m}_{1}=0.1712 \\
& \mathrm{a}_{22} \mathrm{~m}_{2}=0.6270
\end{aligned}
$$

Simultaneously, since it is an input-output table, the sum of the column input coefficients is 1.

$$
\begin{aligned}
& a_{11}+a_{21}+a_{K 1}+a_{L 1}=1 \\
& a_{12}+a_{22}+a_{K 2}+a_{L 2}=1
\end{aligned}
$$

$\mathrm{a}_{\mathrm{K} 1}, \mathrm{a}_{\mathrm{L} 1}, \mathrm{a}_{\mathrm{K} 2}$, and $\mathrm{a}_{\mathrm{L} 2}$ are the input coefficients for the capital stock and labor of forestry and other sectors, respectively. In the vertical columns, the totals for capital and labor are expressed as the gross value added to forestry and other 
sectors, so $\mathrm{a}_{\mathrm{K} 1}+\mathrm{a}_{\mathrm{L} 1}$ and $\mathrm{a}_{\mathrm{K} 2}+\mathrm{a}_{\mathrm{L} 2}$ can be obtained by taking the ratio of the gross value added to the total costs for forestry and other sectors, respectively. This ratio is obtained by parameter estimation using the ordinary least squares method, with the total costs as the explanatory variable, the gross value added as the independent variable, and a constant term of zero $^{2}$ (Note 2 ).

$$
\begin{aligned}
& \mathrm{a}_{\mathrm{K} 1}+\mathrm{a}_{\mathrm{L} 1}=0.6449 \\
& \mathrm{a}_{\mathrm{K} 2}+\mathrm{a}_{\mathrm{L} 2}=0.5362
\end{aligned}
$$

This allows us to solve the simultaneous equations by the formula given above, yielding the following results:

$$
\begin{array}{ll}
\mathrm{m}_{1}=0.5133 & \mathrm{~m}_{2}=1.3548 \\
\mathrm{a}_{11}=0.0216 & \mathrm{a}_{12}=0.0010 \\
\mathrm{a}_{21}=0.0010 & \mathrm{a}_{22}=0.0010
\end{array}
$$

\subsection{Deviation between Optimal and Actual Input Coefficients $t$}

Let's observe the deviation between optimal and actual input coefficients. The input coefficients derived above are optimal in the sense of minimizing costs. We will subtract them from the actual values.

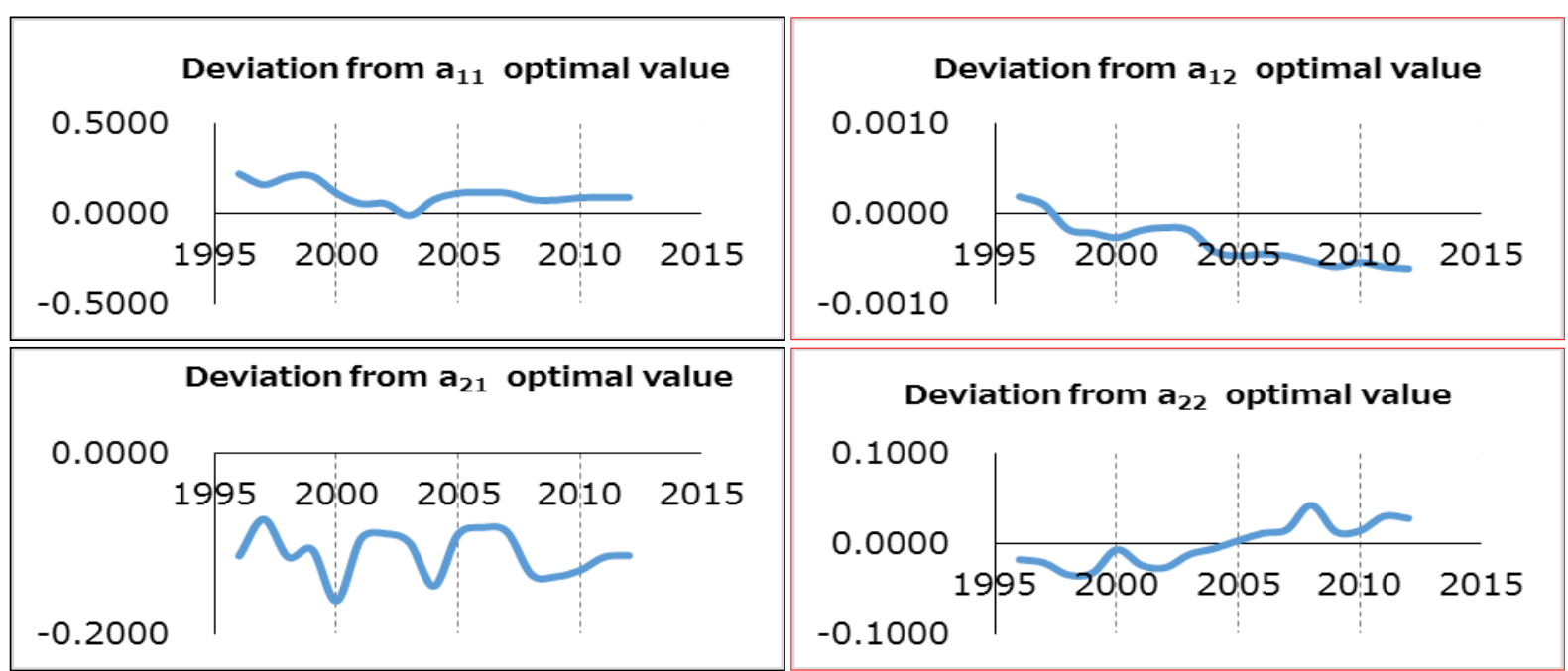

Figure 1. Deviation between optimal and actual input coefficients

Figure Legends: Deviation between optimal and actual input coefficients

Note: The time period for the a21 graph is also $1996-2012$.

A positive value means too much trade, and a negative value means too little trade. Let's calculate the average deviation of input coefficients.

$$
\begin{array}{ll}
\text { deviation of } \mathrm{a}_{11}=0.1206 & \text { deviation of } \mathrm{a}_{12}=-0.0002 \\
\text { deviation of } \mathrm{a}_{21}=-0.1119 & \text { deviation ofa } \mathrm{a}_{22}=-0.0041
\end{array}
$$

From these values, we can state the following about each input coefficient:

$$
\begin{aligned}
& \mathrm{a}_{11}: \text { too large } \\
& \mathrm{a}_{12}: \text { nearly optimal } \\
& \mathrm{a}_{21}: \text { too small } \\
& \mathrm{a}_{22}: \text { nearly optimal }
\end{aligned}
$$

These numbers mean that there is too much intermediate trade among forestry players, while the flow of intermediate products from other sectors to forestry is too small. This demonstrates the closed nature of forestry.

The size of the deviation between the optimal and actual values for input coefficient a11 indicates that trade in intermediate products among forestry players should be reduced by almost $12 \%$ on average. At the same time, we see that for input coefficient $\mathrm{a}_{21}$, which indicates the flow from other sectors into forestry, the actual value falls short of the optimal value by approximately $11 \%$. These calculations tell us that in order to optimize production activities, the $11 \%$ reduction among forestry players should be used to increase intermediate products from other sectors by a corresponding amount. 
It is necessary to break open the closed nature of forestry and ramp up trade with other sectors. Specifically moving away from the existing forest management practices, in which only forestry companies handle forestry business and business is done only between forestry companies is imperative, instead proactively entrusting non-forestry sector companies to perform work that they could conducted more efficiently. This would mean procurement from other industries instead of the forestry industry, thus opening up forestry.

This should eliminate Japanese forestry's insularity and further increase intermediate inputs from other industries.

\section{Potential for Entry by Other Industries into Forestry}

We discuss the necessity of bringing in intermediate products from other industries to create an industrial structure that raises productivity. This means increasing commissions to other industries of work that were done by other forestry companies and to open up work that was done by other forestry companies to other industries.

\subsection{Potential for Entry by Construction Companies}

\subsubsection{Potential for Entry}

Regional construction industries have a surplus of workers, while forestry has a shortage. Yoneda (2012) suggests that regional construction companies enter the forestry industry, given first their potential for labor mobility and second their high affinity with forestry, since they are involved in land reclamation and erosion and flood control projects.

\subsubsection{Challenges to Entry}

Yoneda indicates that while there are no legal barriers to new entrants in forestry, there are practical barriers, such as cumbersome subsidy applications, the complexity of forest classifications, and the asymmetry of forest information. The complexity of forest classifications is a particular hindrance to new entrants. For example, there are a variety of limitations in forest management in the case of protected forests. Permission from the prefectural governor is required for felling, and advance notice is required for thinning. One instance of asymmetrical forest information is the forest registry, which records the state of forests. This is an important resource for learning forest information, but only forestry cooperatives are permitted to have copies, and this information is not disclosed to other industries. Such issues effectively function as entry barriers.

In addition, of course, the biggest challenge at present is that the construction industry, with no forest management machinery or equipment and no technical skills, cannot become involved immediately. However, it is also a fact that forestry, with its low levels of profitability, is not attractive to construction companies with large revenue bases, so the construction industry is unlikely to move quickly to solve these problems.

\subsubsection{Solving the Problems}

Conversely, however, the removal of the barriers that Yoneda mentions would enable the construction industry's entry. Issues involving procedures and informational asymmetry are in the process of being resolved by easing regulations. Changing the structure of forestry through cross-industry collaboration to make it more attractive to the construction industry is also critical.

\subsection{Potential for Giving Business to Nonprofit Organizations}

\subsubsection{Potential for Entry}

According to Yamamoto (2003), the most important group that can currently be involved with forestry is that of forest volunteers. A questionnaire survey conducted by Shimada Shumpei in 2003 found that $72.7 \%$ of forest owners supported forest improvements by volunteer groups. ${ }^{3}$ (Note 3) It is meaningful for forest volunteer groups to engage in such specific activities as forest management practices. For some people, forest volunteer activities are a form of community service, and for others, they are an opportunity to learn forestry knowhow. Certain forest management activities also give the perception of contribution to society. A survey contained in the Forestry Agency's FY2000 report indicated "social contribution" to be the number-two reason for participating in forestry volunteer work. ${ }^{4}$ (Note 4 ) Indeed, forest owners and NPOs need each other.

Forest management practices can be broadly divided into planting, nurturing, and felling. Of these, the one that does not require large machinery and equipment is nurturing, making it relatively easy for even NPOs to enter.

\subsubsection{Challenges to Entry}

There are many advantages to having NPOs engage in forest management, but it is difficult to imagine that NPOs would be able to immediately implement the forestry knowhow that the forestry industry spent so many years building up. The nurturing tasks described earlier as being possible to start working on are called "weeding," which refers to the cutting away of underbrush around the trees that have been planted. In addition to acquiring the technical skills involved in operating a mower, those performing this task must be able to distinguish between brush and planted trees. Planting 
requires predicting locations where trees will grow well, and felling requires purchasing machinery as well as judging how best to fell and transport trees - tasks that are currently difficult for NPOs to perform. One future challenge is to build a mechanism for transferring the forestry industry's technical skills to NPOs. There is also concern that volunteer organizations, not being legal entities, may go out of existence and not be able to continue their subcontracting work.

\subsubsection{Solutions}

One solution to these challenges is to bring in NPOs and other social businesses. The plan is to reduce transactions between those engaged in forestry and open up that portion of the business to NPOs and similar organizations. ${ }^{5}$ (Note 5) With the increase in environmental awareness in recent years, the number of forest volunteer NPOs is rising steadily. These NPOs have established management and accounting and are in a position to assume responsibility while also ensuring continuity.

This proposal would also lead to the further development of Japanese social businesses. Many Japanese nonprofits depend on subsidies and have no autonomous, established social businesses.

Participation in the forestry industry, as proposed here, can be seen as an opportunity for nonprofits to further develop and nurture their social businesses. Nonprofits, acting as a bridge between the people and the forestry industry, with its reputation of being closed, should create opportunities for citizens to become involved in the business of forestry.

\section{Summary}

We have demonstrated quantitatively the closed nature of the forestry business, which is one of the problems that have plagued forestry for many years. This is the first time that the closed nature has been demonstrated using input-output analysis. Specifically, we were able to show quantitatively that reducing intermediate product transactions among members of the forestry industry by an average of about $12 \%$ and offsetting them with transactions with other industries will optimize trade in the forestry industry.

Opinions will likely continue to diverge on the question of what to substitute as trade with other industries. Given the various types of industries and the need to take future technical progress into account, explaining this simply is an important matter. In addition to mentioning regional construction industries as potential new entrants, which was proposed previously, we also suggested setting up more nonprofits and other forest-related social businesses. We were able to suggest one idea for entry by nonprofits into forestry in the form of forest-related social businesses.

Although we suggested that construction companies and nonprofits enter forestry, entry by other industries is also conceivable. The $2 \times 2$ sector analysis methodology used in this paper made it impossible to put forth specific numbers for how to increase intermediate inputs from other industries, such as the construction sector and nonprofit activities. In the future, it will be necessary to further subdivide the number of sectors, such as the construction industry and the NPO sector. Performing such analyses will permit us to identify more appropriate and specific metrics for forestry trade and present a more in-depth theory.

The development of the Japanese forestry industry will also lead to environmental conservation through forest improvement. The healthy development of forestry will contribute to the sustainable growth of the natural environment in Japan. We hope to press forward with further research on the problem of the closed nature of forestry, thereby contributing to the development of forestry in Japan.

\section{References}

Mizuno, K. (1992). A Study on System-wide approach. Tokyo, Azusashuppan, 229.

Okumura, F., \& Katsura, T. (2006). Basical Studies on the Forest Volunteer Works and Non-Profit Organization (NPO). Kokusai Kenkyuи Rongyou, 19(2), 141-153.

Takayanabi, D., Takahashi, M., \& Imase, M. (2002). Economic Analysis on NPO by I. O. RETI Discussion Paper Series, 02-J-010.

Theil, H. (1980a). The System-wide approach to microeconomics. Chicago, University of Chicago Press, 260.

Theil, H. (1980b). System-wide explorations in international economics, input-output analysis, and marketing research. Amsterdam, North-Holland Publishing Company, 143.

Yamamoto, N. (2007). Input-Output Analysis of Forest Sectors in Japan and Austria. Forest resources and mathematical modeling, 6, 89-99.

Yamamoto, S. (2003). Theory about volunteer activities in a forest, J-FIC, 345.

Yoneda, M. (2012). A study on local construction industry entering the agriculture and for depopulated area. Graduate School of Frontier Sciences. University of Tokyo, 228. 


\section{Notes}

Note 1. Input-output tables are based on the Ministry of Internal Affairs and Communications' input-output tables and extended tables for 1995, 2000, 2005, and 2011. See the appendix for the methodology for converting this into a 2 $\mathrm{x} 2$ table.

Note 2. The input-output tables make no explicit distinction between $\mathrm{K}$ and $\mathrm{L}$, so we added $\mathrm{K}$ and $\mathrm{L}$ to obtain the gross value added. Taking the gross value added, $\mathrm{G}$, from the input-output table as the sum of $\mathrm{K}$ and $\mathrm{L}$, we created the following equations in accordance with the definitions. aG1 $(=\mathrm{aK} 1+\mathrm{aL} 1)$ is input coefficient for the gross value added for the forestry column, and $\mathrm{aG} 2(=\mathrm{aK} 2+\mathrm{aL} 2)$ is the input coefficient for the gross valued added for the "other sector" column. We estimated that

$$
\begin{aligned}
& \text { Nominal value of }\left(\mathrm{K}_{1}+\mathrm{L}_{1}\right)=\mathrm{a}_{\mathrm{G} 1} \mathrm{C}_{1} \quad \text { and } \\
& \text { Nominal value of }\left(\mathrm{K}_{2}+\mathrm{L}_{2}\right)=\mathrm{a}_{\mathrm{G} 2} \mathrm{C}_{2}
\end{aligned}
$$

This enables us to estimate $\mathrm{a}_{\mathrm{G} 1}$ and $\mathrm{a}_{\mathrm{G} 2}$.

Nominal value of $\left(\mathrm{K}_{1}+\mathrm{L}_{1}\right)=0.6449 \mathrm{C}_{1}$

$$
\mathrm{R} 2=0.9777 \quad \mathrm{~S} 2=74717.8
$$

Nominal value of $\left(\mathrm{K}_{2}+\mathrm{L}_{2}\right)=0.5362 \mathrm{C}_{2}$

$$
\mathrm{R} 2=0.9982 \quad \mathrm{~S} 2=19686837.2
$$

The estimation period is 1996-2012.

Note 3. Shimada's survey is included in Yamamoto (2003), pp. 103-104.

Note 4. The Forestry Agency survey is presented in the Fiscal 2000 Annual Report on Trends in Forests and Forestry, p. 45, Figure 4, "Primary Motivators for Forest Creation Activities" (Forestry Agency working materials). http://www.maff.go.jp/hakusyo/rin/h12/html/index.htm

Note 5. NPOs are treated as "Private Non-profit sector," which was the method used in preparing the "2000 input-output tables for analyzing NPOs" from the Research Institute of Economy, Trade and Industry, which served as the basis for the analysis done by Takayanagi, Takahashi, and Imase (2002). This "Private Non-profit sector" is included in "other sectors" in our 2 x 2 input-output table. In other words, NPOs are included in "other sectors." This supports the theory that trade among forestry players should be reduced by transferring an equivalent amount to NPOs. 


\section{Appendices}

\section{Notes on data}

For forestry prices, we used indices created by the authors using the Laspeyres method and data for cypress, cedar, and larch, taking 2005 as the base year.

For calculating actual domestic production value for forestry, we used the forestry price indices above.

For calculating actual domestic production value for other sectors, we used the weighted-average domestic corporate goods price index, taking 2005 as the base year.

For calculating the real input values from forestry to forestry, we used the forestry price indices above.

For calculating the real input values from forestry to other sectors, we used the forestry price indices above.

For calculating the real input values from other sectors to forestry, we used the weighted-average domestic corporate goods price index, taking 2005 as the base year.

For calculating the real input values from other sectors to other sectors, we used the weighted-average domestic corporate goods prices index, taking 2005 as the base year.

For calculating the real final demand for forestry, we used the overall consumer price index, taking 2005 as the base year.

For calculating the real final demand for other sectors, we used the overall consumer price index, taking 2005 as the base year.

For interest rates (the price of capital), we took the domestic bank lending rate converted into real terms by subtracting the growth rate of the weighted-average domestic corporate goods price index $(2005=100)$.

For wage indices, we used the monthly statistical survey from the Ministry of Health, Labour and Welfare.

\section{Constructing the 2 x 2 input-output table}

We kept forestry and consolidated all other sectors into one. We prepared $2 \times 2$ input-output tables for the period up to 2012.

\section{Creating the updated input-output table}

The input-output tables prepared by MIAC are for 1995, 2000, 2005, and 2011. MIAC releases extended tables in each fiscal year. Based on those materials, the authors prepared updated input-output tables for the forestry sector.

\section{Copyrights}

Copyright for this article is retained by the author(s), with first publication rights granted to the journal.

This is an open-access article distributed under the terms and conditions of the Creative Commons Attribution license which permits unrestricted use, distribution, and reproduction in any medium, provided the original work is properly cited. 